\title{
Reference Scenarios for the Deployment of Emergency Communications for Earthquakes and Mass Transport Accidents
}

\author{
Haitham Cruickshank \\ ETSI SatEC group, STF 472 team \\ h.cruickshank@surrey.ac.uk
}

Egil Bovim

ETSI SatEC group, STF 472 team

egil.bovim@gmail.com

\author{
Anton Donner \\ ETSI SatEC group, STF 472 team \\ anton.donner@dlr.de \\ Julian Sesena \\ ETSI SatEC group, STF 472 team \\ julian.sesena@wirelesspartners.es
}

\author{
Robert Mort \\ ETSI SatEC group, STF 472 team \\ mort.robert@gmail.com
}

\begin{abstract}
Voice-based Private Mobile Radio (PMR) networks are currently the state-of-the-art for coordination of disaster response works. The increasing availability of digital data on one hand and the advantages of IT-based command and control systems on the other, create a need for data networks between the incident area and back office command and control structures. During major incidents, commercial public networks might be damaged or overloaded, and current digital PMR networks do not support data rates beyond several kbit/s. Satellite communication can play an important role to complement existing terrestrial networks because of their inherent independence from terrestrial infrastructures, wide coverage and multicast capacity. However, in order to devise the best solution, it is important to capture and model user operating modes, communication needs as well as the topological characteristics of user deployment and motion. These findings are synthesised in what is called a "scenario". This paper describes the current work within the ETSI STF472 in the SatEC working group on small to large scale emergency scenarios. A general overview of rescue response roles is also described together with communication network requirements and flows. Future work will focus on producing more detailed satellite network requirements and network topological models showing how entities involved and their roles are deployed during the incident response.
\end{abstract}

Keywords- satellite networks; Earthquakes, Mass transport accident; Mass casualty incidents, communication requirements

\section{INTRODUCTION}

Major emergencies or disasters may result in a need for additional resources in local telecommunications networks. Especially if they are damaged or overloaded, in order to maintain or enhance the ability of rescue workers to respond and coordinate their activities effectively [4], [5]. Satellites have new advanced role in replacing or supplementing other telecommunications links in these scenarios. For example satellite systems can provide:
- Fast, deployable broadband and secure communication facilities anywhere/anytime in locations where no facilities are available.

- Pocket size voice and narrowband data communications anywhere/anytime.

- Temporary replacement of broken/saturated infrastructure trunks by means of backhauling.

- Efficient broadcast of early warning and tactical data to wide areas.

- Economical network deployment in comparison with full terrestrial coverage, especially in geographically wide and remote areas.

In order to identify, position and dimension the required capabilities offered by satellite terminals in emergency situations, a set of standardised requirements needs to be established. However, it requires a proper methodology to capture the responders' requirements and translate them into engineering aids without introducing any a priori technology bias.

The approach adopted is to provide "reference" scenarios in order to establish a basis for evaluation and dimensioning of telecommunications requirements. In this case a reference scenario is a definition of a situation encompassing a typical event that causes the emergency situation, and of the subsequent specific responses (e.g., search-and-rescue; logistics; first aid; shelter etc.). For each type of response the main parameters dimensioning the activity will be defined (e.g., the number of injuries, number of displaced people etc.), together with a qualitative and quantitative evaluation of the information exchange needs.

Extensive interactions with end-users (civil protection forces/authorities, fire departments, emergency medical service and NGOs) are conducted for refinement of the 
reference scenarios to ensure they are realistic. Experience has shown that it is difficult to attract these users to meetings of Technical Bodies (TBs) in standards organisations especially in a short timescale, so pro-active contacts are made.

The focus of current work is on two types of pre-defined emergency scenarios [6], [7]: a mass public transportation accident in the countryside resulting in a Mass Casualty Incident (MCI) and a major earthquake (EQ) over a large area including an urban environment. These scenarios are chosen because the potential lack of telecommunication infrastructure, highlights the vital role that satellites can play in quickly establishing the communication networks. Also they represent large and small scale scenarios, where the communication needs will be different.

The methodology used in this work is that the definition of these scenarios with input from emergency institutional users. This will lead to providing the relevant information to support the process of identifying, describing and dimensioning of communication needs of the emergency responders. Also these scenarios will help to identify the information exchanged between various entities. In parallel, topological characteristics of user deployment and motion are modeled. By coupling topology modeling and information exchanges definition, it is possible to assess the fitness of a given communication technology or to dimension the required resources.

\section{MASS TRANSPORT ACCIDENT (MTA) SCENARIO}

The MTA scenario is chosen to be sufficiently generic to be considered not only for mass transportation accidents, but representative of other causes (i.e. MCIs), and thus to allow relevant communication characteristics for current and future needs to be established.

Any major incident or accident can lead to an MCI. It is characterised by a misbalance between available Emergency Medical Services (EMS) resources and patients requiring medical care. The threshold for an MCI depends on deployable resources and will typically differ between e.g., urban and rural settings.

The main objective of MCI response is to provide fast and adequate help to a maximal number of patients. This requires a comprehensive situation overview. MCIs are typically sudden incidents with little lead time and stringent requirements in terms of logistics efficiency.

In order to meet these requirements regular EMS procedures have to be switched to a temporary "overload mode" involving additional operational and tactical structures. There is a need for a high number of difficult decisions to be made, but a major obstacle is that the situation continuously evolves over time with arriving rescue forces, transport means, and updated incident information. Additionally, the MCI can have a spatial dimension complicating the situation assessment and information exchange [11].

The envisaged scenario is a mass transportation accident in a rural environment, covering a small geographic area (in contrast to the Earthquake scenario, described in the next section). An MCI is a consequence of many people requiring help in comparison to limitations in:

- Rescue personnel in general and more specifically medical personnel like paramedics and emergency doctors.

- Medical supplies like dressing material, infusions, and medicines.

- Medical tools like handbarrows, suction pumps, and assisted-breathing devices.

- General shelter equipment like blankets, and water/food.

- Transport like ambulance cars, buses, or helicopters.

- Hospital treatment capacity and shelter capacity.

\section{A. MCI disaster response actions}

Efficient MCI handling requires several concurrent actions. All affected persons have to be assessed and registered first ("triage") so that their further treatment and transport can be prioritised according to their actual needs and according to the available resources in terms of medical personnel, transport means and hospital capacities. In other words: the right patient should as much as possible get the right treatment at the right time. Here is a brief overview of the most important tasks:

- Search and rescue (SAR): such as rescue/evacuation out of hazard zone (e.g., firefighting, breathing protection and surface water rescue).

- Patient assessment (triage) and registration.

- Identification and treatment/transport of most urgent patients (considering the available resources).

- Mapping of patients to transport means.

- Mapping of transport means with patients to hospitals.

- Supervision of available hospital treatment capacities.

In Fig. 1, a typical MCI process chain with the patient flow (for typical health assistance response) is shown. This diagram is a simplification of actual rescue operation dynamics since it does not consider the spatial and temporal dimensions of the incident. The colour code used in the picture represents patient needs although the triage categories differ between countries.

Ideally, the triage areas should be optimally placed in relation to the logistics, but common experience is that the location(s) of the triage area(s) are self-organising. The incident commander decides if an interim care centre with functionality ranging from weather protection to field hospital facilities has to be set up. 


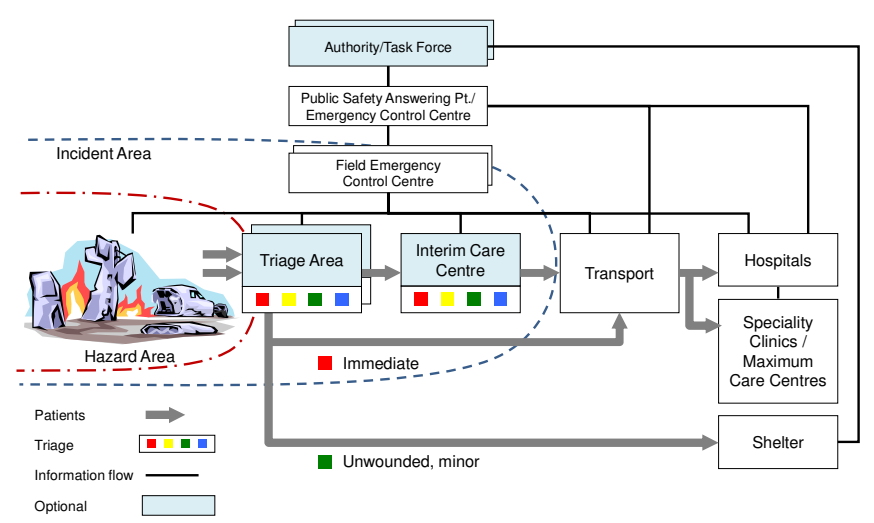

Fig. 1. Theoretical MCI process chain

A chief medical officer (or a medical incident command team) in the field is typically in charge of taking decisions related to patient treatment and transport to suitable hospitals. The information exchanges during the incident can be roughly divided into three macroscopic groups [10]:

- Within the incident area: everything which is related to gathering information about affected persons and their current location in the MCI process chain.

- Between field emergency control centres and back office emergency control centres: the decision makers in the field require information about available transport and treatment capacities. In the opposite direction the emergency coordination centre requires information on actual demand in the field.

- Between the emergency control centre and resource providers (e.g., hospitals, shelter, transport mean providers, other infrastructures): information on available or mobilised resources.

Communication between the incident command in the field and back office entities is currently realised with voicePMR systems. Sometimes these systems support very limited data transmission which is used for alerting and/or fleet management purposes, but other applications can hardly be supported because of the very low data rates. Hence, other data communication networks are required to bridge this gap - and terrestrial networks are not necessarily available in a rural environment. Satellite communication would be a suitable means to provide the infrastructure for all patientlogistics activities plus backhauling emergency control centres and back offices.

\section{EARTHQUAKE (EQ) SCENARIO}

The scenario is defined in terms of its main constituent events (e.g. land movement etc.) and secondly by its physical consequences (e.g. subsequent damage). Subsequently the response actions by emergency forces to this scenario are defined in terms of the number of casualties involved, their condition and position (able to move around/ hidden and stuck under rubble); plus the actors and organisations, overall operating modes and duration.
This scenario is chosen to be sufficiently generic to be considered representative of many earthquakes, and thus to allow relevant communication characteristics for current and future needs to be established.

The main assumption is that the earthquake affects a large area including an urban area. The earthquake is assumed to be of a magnitude sufficient to cause a multitude of physical effects, such as collapsed buildings, flashfloods/tsunamis, disruption of infrastructure with resulting traffic accidents, lack of power, lack of telecommunications, fires, risks of chemical accidents etc. Each of these incidents may not differ much from isolated similar incidents of this nature, but the added challenge is that the incidents happen at the same time at various places, thus reinforcing the effects and strains on available resources. Here are some example effects of an earthquake:

- Physical effects such as collapse of buildings, fire and chemical accidents.

- Disruption of infrastructure such as power, water, sanitation and transport and telecommunications.

- Disruption to services: such as emergency services (police, fire services, health services).

\section{A. EQ disaster response actions}

A major earthquake may be seen as a number of simultaneous MCIs within a given geographic area. In addition to the tasks described in the MCI section above (see II.A), the following extra tasks are required due to the large scale of an EQ compared to MCI scenario:

- Extra situation/resource assessment for dangers such as building collapse, flooding and chemical accidents.

- Evacuation of population: such as evacuation to temporary dwellings.

- Emergency shelters: such as temporary housing, food supply, water supply, electricity, sewage.

The tasks to be undertaken will be broadly similar between earthquakes but, depending on local/ national organisation of services and division of tasks/ responsibilities, the entities involved and their individual areas of work may differ. Depending on the severity of the earthquake, resources may be drawn nationally, regionally and internationally (e.g. involving fire-fighters from several countries).

\section{COMMUNICATION LINKS BETWEEN EMERGENCY ENTITIES}

Fig. 2 depicts the main involved entities/roles and typical communication links [1], [2], [3]. The disciplines for technical/medical rescue, care and police are shown as "rescue disciplines A, B, C". Depending on the incident there might be none, one or many Field Emergency Control 
Centres (FECCs) for each rescue discipline operating in a hierarchical structure e.g the medical rescue command structure might have dedicated FECCs for the triage area, for the interim care centre, and for the transport section. For the EQ scenario, there will be multi-disciplinary rescue teams: for example discipline A (fire\& rescue team), Discipline B (health and medical emergency team) and Discipline C (police or state armed forces).

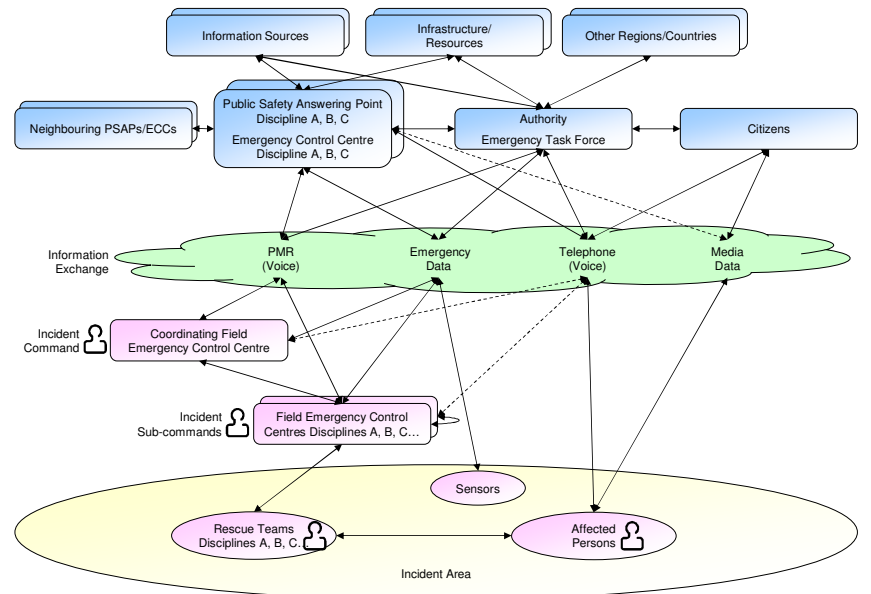

Fig. 2. Typical communication links between emergency entities/roles

Some of the communication flows between various entities (in Fig. 2) are described below. Note that several described applications are not yet widely-used, so that the descriptions are anticipations of future developments:

- $\quad$ FRs to FRs: For example, the First Responders (FRs) in each rescue team (discipline $\mathrm{A}, \mathrm{B}$ or $\mathrm{C}$ ) has its own and unique talkgroup.

- FRs to corresponding FECC: Bidirectional voice communication is allowed between the FRs and their FECC since they share the same voice group. Bidirectional data communication is allowed also between FRs and their FECC primarily for geopositioning applications. Special data services are required for the fire $\&$ rescue discipline in the hazard area since they may carry special equipment which needs to transmit data to the corresponding FECC. Examples of this equipment are wearable biometric sensors, radiation or gas sensors, video cameras, positioning equipment. FECCs should have equipment to receive, integrate and display all these data acquiring valuable risk management information. Crucial actions are allowed, i.e. FRs could be rescued if irregular vital constants are observed. FRs will receive alerts, positioning information, commands to proceed, etc, through voice communication or data displayed on their user interface.

- FECC to FECC: In case several FECCs are deployed, they all should have bidirectional communication among them sharing valuable risk management information from their corresponding Coordinating FECC (CFECC).

- FECC to AETF: All FECCs deployed in the disaster area and the global coordination centre (Authority Emergency Task Force, EATF) in Fig. 2, should have bidirectional voice and data communication among them sharing valuable risk management information or commands to proceed.

- FECCs/CFECC to External entities: Certain control centres have bidirectional communications with external entities with or sometimes without the intervention of the AETF, such as fire \& rescue communicate with medical vehicles with hospitals. In addition to current operational practices where just voice calls are performed, paramedical users have suggested to enable ambulances to send data files with injured victims lists or electrocardiogram (ECG) traces to the hospital to reduce reaction time attending the victims.

- FECCs/CFECC to External information sources: It is desirable for control centres to have external connections in order to enhance effectiveness of the operational procedures. One example is access to detailed maps for geo-localisation support units would receive detailed information of the target location. Another application could be accessing the fire risk assessment indices of the affected area which takes into account baseline vegetation information (vigour, condition, etc). Access to near real-time satellite images is a new service provided by current earth observation LEO satellites in charge of image acquisition of the hot spots within several hours from the start of the emergency.

The information exchange cloud in Fig. 2, represents the communication network that is required for the above entities to communicate and share information.

\section{COMMUNICATIONS SERVICES REQUIREMENTS}

In Fig. 2, the efficient exchange of information within single discipline teams, between FECCs, CFECC and Public Safety Answering Point (PSAP) may be facilitated by a number of communication services, described below [2], [8]:

\section{A. Speech services}

Speech services are currently the most instinctive and most used communication services in emergencies. As such there exist several universal requirements, characterised by:

- Speech intelligibility and quality: that received speech is capable of being understood reliably and some cases high speech quality is desirable.

- Call setup-time: short call set-up times enable rapid communication of relevant information.

- End to end delay: in addition to the call set-up delay, it is recognised that where a duplex voice communication system imposes an end to end delay of over $500 \mathrm{~ms}$ there is degradation in the voice quality (ITU T Recommendation G.114). 
Also underlying networks (e.g. satellite and terrestrial) should have the capability to handle prioritised calls correctly, including the capability of pre-emption of unprioritised calls. Transit networks should convey priority related signaling in order to support end-to-end priority. Some examples of speech services are shown below.

- Point-To-Point (P2P) Speech Services: Point to point duplex voice communications are required for many instances to provide communications, particularly between different authorities e.g. between commanders of different emergency services, between emergency service staff and external specialists.

- Push-To-Talk (PTT) over Cellular (PoC) (PoC)/Command and Control (C\&C) features: PoC helps to avoid network congestion by transmitting voice over a data channel (GPRS, UMTS) and thus can be used even in times of high traffic on the communication network.

- Group Speech Services: Two examples of groups are:

- Talk group: Point-to-multipoint group addressed communication established within a selectable predefined area.

- Emergency services call (authority to authority)

\section{B. Video Tele-Conferencing (VTC)}

VTC may be required to enable effective coordination between services at a command level or below. VTC services may be utilised to provide reconnaissance information from the incident back to control rooms. Note that near-real-time video streaming can be considered as a data service (see below).

\section{Data services}

Data services are used to provide a large number of applications which can have widely differing requirements in terms of capacity, timeliness and robustness of the data service. Ideally, the communication networks should support the required data throughput and minimise end to end delay, especially for applications such as real time video. Noting the extreme circumstances which may be in force during an emergency, it may be desirable for networks to degrade gracefully when user requirements exceed the agreed levels of service.

Table I shows the diverse needs of data applications. Where data applications share the use of a data transmission capability, provision of sufficient capacity and effective management must be provided to ensure application data is communicated appropriately. The definition of Table I categories are:

- Throughput: data volume in a given time.

- Timeliness: importance of the information arriving within an agreed timeframe.

- Preservation of data integrity: how (reliable) free from bit errors the information transmission needs to be. E.g. a bitmap image with some errors is still useable; a jpg image with some bit errors may be unreadable.

TABLE I. REQUIREMENTS ON DATA APPLICATIONS [2]

\begin{tabular}{|l|c|c|c|}
\hline Service & Throughput & Timeliness & $\begin{array}{l}\text { Need for } \\
\text { preservation of } \\
\text { data integrity }\end{array}$ \\
\hline Email & Medium & Low & Low \\
\hline Imaging & High & Low & Variable \\
\hline $\begin{array}{l}\text { Digital } \\
\text { mapping/ } \\
\begin{array}{l}\text { Geographical } \\
\text { information } \\
\text { services }\end{array}\end{array}$ & High & Variable & Variable \\
\hline $\begin{array}{l}\text { Location } \\
\text { services }\end{array}$ & Low & High & High \\
\hline $\begin{array}{l}\text { Video (real } \\
\text { time) }\end{array}$ & High & High & Low \\
\hline $\begin{array}{l}\text { Video (slow } \\
\text { scan) }\end{array}$ & Medium & Low & Low \\
\hline $\begin{array}{l}\text { Data base } \\
\text { access } \\
\text { (remote) }\end{array}$ & Variable & Variable & High \\
\hline $\begin{array}{l}\text { Data base } \\
\text { replication }\end{array}$ & High & Low & High \\
\hline $\begin{array}{l}\text { Personnel } \\
\text { monitoring }\end{array}$ & How & High \\
\hline
\end{tabular}

However, and from users' feedback the data services are not used in today's handling of earthquakes.

\section{Paging (short message) Services}

Paging (short messages) services are used by a variety of authorities in order to contact their personnel, and paging services are available from a variety of networks and technologies. The network needs to be able to identify the requested authorised emergency agent(s), and then deploy the appropriate technology to contact them. This requirement may encompass different communication network technologies, services and applications such as paging, presence, texting, etc. Again and from users' feedback, the paging services are not used in today's handling of earthquakes.

\section{E. Status Monitoring and Location Services}

Status monitoring includes a wide variety of parameters, e.g. breathing air tank levels, accountability monitoring, distress buttons and vital signs monitoring. Location services provide real-time information regarding the position of personnel or vehicles to FECC. This information may also include status information regarding the person or vehicle. The service may require frequent transmissions to update 
position; the amount of data transmitted is likely to be small when location is based on satellite-based solutions, but can be quite extensive when location is to be calculated inside buildings as other technologies may have to be used. Location reporting services may be one-way with no acknowledgement, necessitating a robust communication mechanism. Position information may be considered sensitive in some emergencies and may require security mechanisms to protect the data.

\section{F. Summary of service requirements}

Based on an assessment of current communication services in the public safety sector, it can be summarised that public safety mobile communications are voice-based with widespread use of group calls ("network-centric"), also called talkgroups. These are called push-to-talk calls. Pointto-point voice calls are also used especially by emergency managers.

According to user comments, positioning information of emergency units deployed in the disaster area is also currently used in most of Public Agencies that counts on narrowband data channels of TETRA technology. However, there is a trend towards using a range of data applications alongside traditional voice applications to enhance communications. Data services have widely differing requirements in terms of capacity, timeliness and robustness of the data service

The current work within ETSI STF472 aims to detail the service requirement for both MTA and EQ. However, in the following is an example requirement for a forest fire, which can be used as a future template for MTA and EQ scenarios. Table II shows a forest fire example with players, vehicles and FECCs when deployed in each fire centre. These numbers are based on the MONET project findings [9]. First emergency units arrive on the biggest fire centre. Emergency responders establish FECC and fire officials assess the situation. Six fire-fighters of each squad approach the wildfire in order to extinguish it, not separating more than $300 \mathrm{~m}$ from their auto-pump vehicle since this is the maximum hose extension. Thus, the auto-pump team, the driver and a fire-fighter, remains in the auto-pump to maintain the water supply. The rest of the emergency responders remain also in the warm area. Finally, three FECCs and their corresponding FRs are set up in hot and warm areas of this second fire centre, starting the second emergency phase which involves higher number of communications since more emergency responders are present in the scenario. It will be assumed that 15 affected people have to be carried to the nearest hospitals. Such information can be used in the future to more detailed terrestrial/satellite network requirements and a topological model showing the telecommunications needs of end-users in each of their activities.
TABLE II. EXAMPLE COMMUNICATIONS REQUIREMENTS FOR FOREST FIRE SCENARIO [9]

\begin{tabular}{|c|c|c|c|c|}
\hline Public safety agency & $\begin{array}{l}\text { Service in } \\
\text { use }\end{array}$ & Users & Comm. flow & Occurrence \\
\hline \multirow{4}{*}{$\begin{array}{l}\text { Fire brigade in } \\
\text { hot area }\end{array}$} & $\begin{array}{l}\text { PTT Voice } \\
\text { Call }\end{array}$ & 120 & $\begin{array}{l}\text { Fire Brigade } \\
\mathrm{CP} \text { from/to } \\
\text { fire-fighters } \\
\text { in hot area }\end{array}$ & $\begin{array}{l}926,4 \\
\text { PTT/15 } \\
\text { minutes } \\
\text { during } \\
\text { busiest hours } \\
463,2 \\
\text { PTT/15 } \\
\text { minutes } \\
\text { during } \\
\text { regular hours }\end{array}$ \\
\hline & $\begin{array}{l}\text { Personnel } \\
\text { monitoring }\end{array}$ & 120 & $\begin{array}{l}\text { Fire-fighters } \\
\text { in hot area to } \\
\mathrm{CP}\end{array}$ & $\begin{array}{l}\text { Nominal } \\
\text { each 5s } \\
\text { while } \\
\text { moving. }\end{array}$ \\
\hline & $\begin{array}{l}\text { Location } \\
\text { services }\end{array}$ & 120 & $\begin{array}{l}\text { Fire Brigade } \\
\text { units } \\
\text { (pedestrian) } \\
\text { to CP }\end{array}$ & $\begin{array}{l}\text { Nominal } \\
\text { each } 1,5 \\
\text { minutes } \\
\text { while } \\
\text { moving. } \\
\text { Each } 5 \text { mins } \\
\text { if stopped. }\end{array}$ \\
\hline & $\begin{array}{l}\text { Real Time } \\
\text { Video }\end{array}$ & 20 & $\begin{array}{l}20 \text { Fire- } \\
\text { fighters in hot } \\
\text { area to CP }\end{array}$ & $\begin{array}{l}20 \\
\text { transmitting } \\
\text { continuously } \\
\text { during all } \\
\text { disaster }\end{array}$ \\
\hline \multirow{3}{*}{ Fire brigade in } & $\begin{array}{l}\text { P2P Voice } \\
\text { Calls }\end{array}$ & $1 \mathrm{CP}$ & $\begin{array}{l}\text { Fire Brigade } \\
\mathrm{CP} \text { to BO and } \\
\text { other CPs }\end{array}$ & $12 \mathrm{P} 2 \mathrm{P} / \mathrm{h}$ \\
\hline & $\begin{array}{l}\text { PTT Voice } \\
\text { Call }\end{array}$ & 40 & $\begin{array}{l}\text { Fire Brigade } \\
\mathrm{CP} \text { from/to } \\
\text { fire-fighters } \\
\text { in warm area }\end{array}$ & 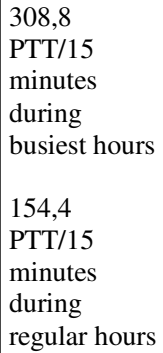 \\
\hline & $\begin{array}{l}\text { Location } \\
\text { services }\end{array}$ & $40+20$ & $\begin{array}{l}\text { Fire Brigade } \\
\text { units } \\
\text { (pedestrian } \\
\text { and vehicles) } \\
\text { to CP }\end{array}$ & $\begin{array}{l}\text { Nominal } \\
\text { each } 1,5 \\
\text { minutes } \\
\text { while } \\
\text { moving. } \\
\text { Each } 5 \\
\text { minutes if } \\
\text { stopped. }\end{array}$ \\
\hline
\end{tabular}




\begin{tabular}{|c|c|c|c|c|}
\hline & $\begin{array}{l}\text { Real Time } \\
\text { Video }\end{array}$ & $1 \mathrm{CP}$ & $\begin{array}{l}\text { Fire Brigade } \\
\mathrm{CP} \text { to } \mathrm{BO}\end{array}$ & $\begin{array}{l}1 \\
\text { transmitting } \\
\text { continuously } \\
\text { during all } \\
\text { disaster }\end{array}$ \\
\hline \multirow{3}{*}{ Medical services } & $\begin{array}{l}\text { P2P Voice } \\
\text { Call }\end{array}$ & $1 \mathrm{CP}$ & $\begin{array}{l}\text { Police CP } \\
\text { from/to BO } \\
\text { and to other } \\
\text { CPs } \\
\text { Medical CP to } \\
\text { hospitals }\end{array}$ & $\begin{array}{l}12 \mathrm{P} 2 \mathrm{P} / \mathrm{h} \\
30 \mathrm{P} 2 \mathrm{P} \\
\text { during all } \\
\text { disaster } \\
\text { considering } \\
15 \text { victims }\end{array}$ \\
\hline & $\begin{array}{l}\text { PTT Voice } \\
\text { Calls }\end{array}$ & 30 & $\begin{array}{l}\text { Medical CP } \\
\text { from/to } \\
\text { doctors/nurses }\end{array}$ & $\begin{array}{l}231,6 \\
\text { PTT/15 } \\
\text { minutes } \\
\text { during } \\
\text { busiest hour } \\
115,8 \mathrm{PTT} / 15 \\
\text { minutes } \\
\text { during } \\
\text { regular hours }\end{array}$ \\
\hline & $\begin{array}{l}\text { Location } \\
\text { services }\end{array}$ & $30+10$ & $\begin{array}{l}\text { Medical units } \\
\text { (pedestrian } \\
\text { and vehicles) } \\
\text { to } \mathrm{CP}\end{array}$ & $\begin{array}{l}\text { Each 1,5 } \\
\text { minutes } \\
\text { while } \\
\text { moving. } \\
\text { Each } 5 \\
\text { minutes if } \\
\text { stopped. }\end{array}$ \\
\hline
\end{tabular}

\section{Conclusion}

This paper has described the current work within ETSI STF 472 (which is part of SatEC working group) on two types of emergency scenarios: Mass public transport accident in the countryside and major earthquake in wide area including urban environment. In such disrupted communication environment, satellites can play a vital role in re-establishment of the needed emergency communication networks.

An overview of user requirement has been given together with communication network requirements and flows. Collecting specific user requirements based on practical experience is an ongoing task. This will help to produce more detailed satellite network requirements and a topological model showing the telecommunications needs of end-users in each of their activities.

Acknowledgements: This work is co-financed by the EC/EFTA in response to the European Commission's ICT Standardisation Work Programme. ETSI produces globallyapplicable standards for Information and Communications Technologies (ICT), including fixed, mobile, radio, converged, broadcast and internet technologies and is officially recognised by the EC as a European Standards Organisation. ETSI is a not-for-profit organization whose 700 ETSI member organisations benefit from direct participation and are drawn from 60 countries worldwide. For more information, please visit: www.etsi.org

About ETSI Specialist Task Forces (STF): STFs are teams of highly-skilled experts working together over a pre-defined period to draft an ETSI standard under the technical guidance of an ETSI Technical Body and with the support of the ETSI Secretariat. The task of the STFs is to accelerate the standardisation process in areas of strategic importance and in response to urgent market needs. For more information see http://portal.etsi.org/stfs/process/home.asp.

\section{REFERENCES}

[1] ETSI TR 102 180: "Emergency Communications (EMTEL); Basis of requirements for communication of individuals with authorities/organizations in case of distress (Emergency call handling)".

[2] ETSI TS 102 181: "Emergency Communications (EMTEL); Requirements for communication between authorities/organizations during emergencies".

[3] ETSI TS 102 182: "Emergency Communications (EMTEL); Requirements for cimmunications from authorities/organizations to individuals, groups or the general public during emergencies".

[4] ETSI TR 102 641: "Satellite Earth Stations and Systems (SES); Overview of present satellite emergency communications resources".

[5] ETSI TR 103 166: "Satellite Earth Stations and Systems (SES); Satellite Emergency Communications (SatEC); Emergency Communication Cell over Satellite (ECCS)".

[6] ETSI TS 103 260-1: "Satellite Earth Stations and Systems (SES); Reference scenario for the deployment of emergency communications; Part 2: Earthquake"

[7] ETSI TS 103 260-2: "Satellite Earth Stations and Systems (SES); Reference scenario for the deployment of emergency communications; Part 2: Mass casualty incident in public transportation"

[8] ITU-T Recommendation G.1010: End-user multimedia QoS categories

[9] MONET EU project: http://monet.tekever.com/ July2012

[10] A. Donner, T. Greiner-Mai and C. Adler, "Challenge Patient Dispatching in Mass Casualty Incidents". In: Proceedings of the 9th International Conference on Information Systems for Crisis Response and Management (ISCRAM). (Vancouver, Canada). Ed. by Leon Rothkrantz, Jozef Ristvej, and Zeno Franco. Apr. 2012. isbn: 978-086491-332-6.

http://www.iscramlive.org/ISCRAM2012/proceedings/303.pdf.

[11] A. Donner, C. Adler, M. Ben-Amar and M. Werner, "IT-Supported Management of Mass Casualty Incidents: The e-Triage Project". In: Proceedings 5th Future Security Research Conference. (Berlin, Germany). Sept. 2010. ISBN: 978-3-8396-0159-4. 